\title{
Effect of Peroxide Modification on Melt Fracture of Linear Low Density Polyethylene during Extrusion
}

\author{
Youn Cheol $\mathrm{KIM}^{\dagger}$ and Kyoung Sun YANG \\ Compounds \& Application $R \& D$ Team, Research and Development Center, \\ Samsung Chemical Group, 103-6 Moonji-Dong, Yusong, Taejon 305-380, Korea
}

(Received October 23, 1998)

\begin{abstract}
A commercial linear low density polyethylene (LLDPE) was modified by adding a small amount dicumyl peroxide $(\mathrm{DCP})$ during extrusion at moderate processing temperature $\left(200^{\circ} \mathrm{C}\right)$. The effects of peroxide modification were to change the molecular weight and rheological properties, as evident by increase in high molecular portion, shear sensitivity and melt viscosity at low frequency region. These effects were confirmed by gel permeation chromatography (GPC) and Rheometric dynamic spectrometer (RDS). One outstanding feature of peroxide modification was the remarkable delay in the onset of melt fracture upon extrusion. The dilution of DCP in polypropylene (PP) powder was more effective for improvement of these properties than by direct loading of DCP. The observed remarkable delay in melt fracture is believed to be due to increase in high molecular portion by producing long chain branch and crosslinking. That is, DCP modification results in delay in the onset of melt fracture through increase in high molecular portion which can resist high elongational stress when leaving the die. KEY WORDS Peroxide Modification/Linear Low Density Polyethylene/ Long Chain Branch / Melt Fracture/
\end{abstract}

For more than 30 years it has been known that a polyethylene melt passing through a die may exhibit flow instabilities during constant speed extrusion. ${ }^{1-5}$ These phenomena, visually observed as distortions of the extrudate, are serious problem in polymer processing, limiting the production rates and physical properties of final products. Extrudate distortions range from sharkskin at relatively low flow rates to large amplitude quasiperiodic oscillation in the extrudate diameter and gross melt fraction (wavy melt fracture) at higher extrusion rates. Extrudate distortions are identified as irregular dimensional change in the molten polymer. The dimensional change can be explained by several causes including an inhomogeneous elastic response of the melt to flow fields. ${ }^{6}$

High molecular portion such as long chain branch (LCB) and crosslinking has displayed significant effect on the elastic response and critical shear stress with melt fracture. ${ }^{7-9}$ Melts of linear polymers exhibit extrusion instability, ${ }^{10}$ known as melt fracture, in which there are two critical stresses. The first critical stress is characterized by the visual appearance of regular fine-scale surface distortions known as sharkskin. In the second critical stress, there is an apparent discontinuity in the flow curve, sharkskin disappears, and the extrudate becomes wavy or distorted. This transition is known as wavy fracture or gross melt fracture. For polyethylenes such as linear low density polyethylene (LLDPE) and high density polyethylene (HDPE), fine-scale surface distortion (sharkskin) usually occurs before wavy melt fracture. However, highly branched polyethylene such as low density polyethylene (LDPE) have strong strainhardening elongational behavior and do not exhibit sharkskin defect or surface irregularities even though sharkskin has been observed by White et al. ${ }^{11}$ Venet and Vergnes ${ }^{4}$ reported that the presence of LCB tends to increase the complex viscosity at low frequency region and reduce the aptitude to melt fracture by increasing the tensile resistance during the extrusion of LLDPE.

Polymer modification by adding a small amount peroxide is becoming more widely accepted the method for altering high molecular portion. ${ }^{12-15}$ These are the reasons that the relationship between peroxide modification and rheological behavior of polymers is a topic of long-standing interest. The peroxide initiated mechanism of degradation has been studied by many researchers. ${ }^{12,14}$ The generally accepted reaction mechanism includes the initiated thermooxidative degradation of polyolefines. These reactions are the essence of polyethylene crosslinking and LCB formation.

One application in extrusion of LLDPE is to use black jacketing materials for wire and cable insulation. A principal factor in jacketing application of LLDPE is the surface smoothness of insulation material after extrusion. When dicumyl peroxide (DCP) loads directly to LLDPE melt using the common extruder to modify the molecular structure, the extrudate includes crosslinked material resulting from the poor dispersion of DCP at relative high DCP concentration. Although there have been considerable studies on extrusion conditions and mechanism of LCB formation during peroxide modification of LLDPE, little progress has been made in elucidating the peroxide modification-melt fracture relationships and improving the dispersion of DCP.

The present study was carried out to determine the effects of peroxide modification on melt fracture and dilution of DCP in polypropylene (PP) powder on modification performance of LLDPE. Peroxide modification was accomplished with a laboratory-scale twin screw extruder and a systematic study was made on the effects of DCP concentrations and the dilution of DCP in PP powder.

\footnotetext{
${ }_{+}$To whom correspondence should be addressed.
} 


\section{EXPERIMENTAL}

\section{Materials}

Polyethylene used in this study was LLDPE from Samsung General Chemicals of Korea with a melt index $=2.4\left(190^{\circ} \mathrm{C}, 2.16 \mathrm{~kg}\right)$ and a density $=0.923 \mathrm{~g} \mathrm{~cm}^{-3}$. Polypropylene powder was a commercial product made by Samsung General Chemicals of Korea with a melt index $=10.0\left(230^{\circ} \mathrm{C}, 2.16 \mathrm{~kg}\right)$ and a density $=0.921 \mathrm{~g}$ $\mathrm{cm}^{-3}$.

Seven samples were prepared for testing after passing twin screw extruder (Ikegai, 28 $\phi$ ) with three different DCP concentrations $(650,850$, and $1000 \mathrm{ppm})$. The temperature profile was Cylinderl $\left(\mathrm{C} 1,130^{\circ} \mathrm{C}\right) / \mathrm{C} 2$ $\left(150^{\circ} \mathrm{C}\right) / \mathrm{C} 3\left(170^{\circ} \mathrm{C}\right) / \mathrm{C} 4\left(190^{\circ} \mathrm{C}\right) / \mathrm{C} 5\left(210^{\circ} \mathrm{C}\right) / \mathrm{C} 6\left(220^{\circ} \mathrm{C}\right) /$ $\mathrm{C} 7\left(220^{\circ} \mathrm{C}\right) / \mathrm{Die}\left(225^{\circ} \mathrm{C}\right)$. The screw rpm was 260 and amount of extrudate, $16 \mathrm{~kg} \mathrm{~h}^{-1}$. Formulations of these samples are summarized in Table I. Antioxidant (Irganox 1010, Ciba Geigy) was fixed at $0.1 \mathrm{wt} \%$.

Dilution of DCP in PP powder was carried out with 5 liters flask as follows : the required amount $(100 \mathrm{~g})$ of DCP was accurately weighed into a flask equipped with mechanical stirrer and dissolved in $n$-hexane $(1 \mathrm{~kg})$. A moderate amount of PP powder $(900 \mathrm{~g})$ was added. The flask containing the sample was stirred for $3 \mathrm{~h}$ at $70^{\circ} \mathrm{C}$. The sample was dried for $1 \mathrm{~h}$ at $40^{\circ} \mathrm{C}$ in dry oven.

\section{Measurements}

Molecular weight analysis was carried out with a high temperature gel permeation chromatograph (GPC, Waters-150C). The samples were analyzed at $140^{\circ} \mathrm{C}$ in 1,2,4-trichlorobenzene (TCB) solvent.

Complex viscosity was monitored using Rheometrics Dynamic Spectrometer (RDS, Instec-RDS II) in a parallel plate type of geometry $(12.5 \mathrm{~mm}$ in radius) at $200^{\circ} \mathrm{C}$. Disk-shaped samples were molded at $200^{\circ} \mathrm{C}$ by a laboratory hot press under about 10 metric tons and dried in a vacuum oven for $24 \mathrm{~h}$ before the test. The samples were diameter in $25 \mathrm{~mm}$ and thickness was $3 \mathrm{~mm}$. The gap between the plates was $2 \mathrm{~mm}$. Melt Index was measured using a melt-flow indexer (Ceast-6542).

Onset of melt fracture was determined by observation of the appearance (the surface roughness of extrudate) of extrudates made by Hakke capillary rheometer (Rheocord 90, $L / D=16, D=1.2 \mathrm{~mm}$ ) at $200^{\circ} \mathrm{C}$. The surface of the extrudate was measured by Scanning Electron Microscopy (SEM, ZEOL-JSM 6300). Measured surfaces were coated with gold for the microscopy. Shear stress was measured with a Hakke capillary rheometer $(L / D=16, D=1.2 \mathrm{~mm})$ at $200^{\circ} \mathrm{C}$ as a function of shear rate in order to obtain the critical shear stress of LLDPE resins.

\section{RESULTS AND DISCUSSION}

Effect of DCP Concentration on Melt Fracture of LLDPE

Figure 1 shows the melt index (MI) and melt flow rate ratio (MFRR, MI21.6 kg/MI2.16 kg at $190^{\circ} \mathrm{C}$ ) of the samples before and after loading DCP. The square symbol means direct use of DCP and circle symbol, use of DCP after diluting it in PP powder. As DCP concentration increased, both samples displayed decrease in melt indexes and the increase in MFRR indicated
Table I. Formulation of LLDPE powder and additives

\begin{tabular}{lcccc}
\hline Samples & $\begin{array}{c}\text { LLDPE } \\
\text { Powder/wt } \%\end{array}$ & $\begin{array}{c}\text { DCP } \\
\text { wt } \%\end{array}$ & $\begin{array}{c}\text { PP } \\
\text { Powder/wt \% }\end{array}$ & $\begin{array}{c}\text { Antioxidant } \\
(\text { Ir-1010)/wt \% }\end{array}$ \\
\hline $\mathrm{S}_{\mathrm{b} 0}$ & 99.900 & - & - & 0.1 \\
$\mathrm{~S}_{\mathrm{d} 650}$ & 99.835 & 0.065 & - & 0.1 \\
$\mathrm{~S}_{\mathrm{d} 850}$ & 99.815 & 0.085 & - & 0.1 \\
$\mathrm{~S}_{\mathrm{d} 1000}$ & 99.800 & 0.100 & - & 0.1 \\
$\mathrm{~S}_{\mathrm{p} 650}$ & 99.25 & 0.065 & 0.584 & 0.1 \\
$\mathrm{~S}_{\mathrm{p} 850}$ & 99.05 & 0.085 & 0.765 & 0.1 \\
$\mathrm{~S}_{11000}$ & 99.800 & 0.100 & - & 0.1 \\
$\mathrm{~S}_{\mathrm{p} 1000}$ & 98.900 & 0.100 & 0.900 & 0.1 \\
\hline
\end{tabular}

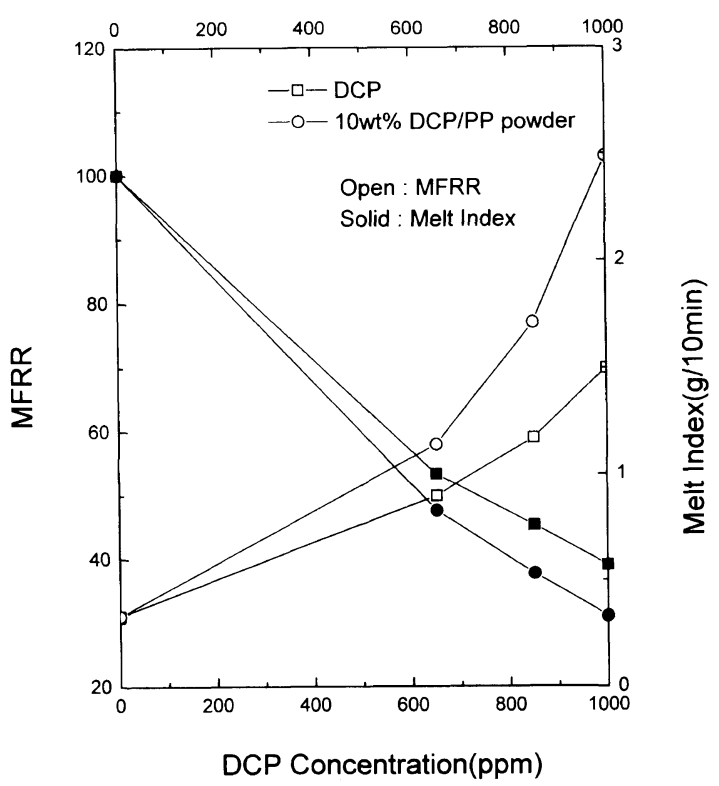

Figure 1. Melt indexes and melt flow rate ratios of LLDPE resins before and after loading DCP

increase in shear sensitivity of LLDPE resin. MFRR is a simple method representing the shear sensitivity of polymer melt. Compared to samples directly loaded DCP, those loaded DCP after diluting it in PP powder display lower MI and higher MFRR within tested DCP concentrations. When optimum DCP concentration was selected for both systems, two factors were considered. One was the existence of non-melting (gel) material on the extrudate surface measured by $\mathrm{T}$-die (width $=10 \mathrm{~cm}$ and thickness $=1 \mathrm{~mm}$ ) in Hakke rheometer. The other was the melt fracture of extrudate.

Suwanda and Balke ${ }^{13}$ reported the critical peroxide concentration for gel formation (calculated by following equation) to be $890 \mathrm{ppm}$.

$$
x_{\mathrm{g}}=1 /\left(2 X n_{\mathrm{w}, 0}\right)
$$

where $x_{\mathrm{g}}=$ crosslink density at gel point,

$n_{\mathrm{w}, 0}=$ initial weight average degree of polymerization of the polymer.

Critical peroxide concentration was $850-1000 \mathrm{ppm}$ for the samples loaded directly DCP. These results are an agreement in Suwanda's result. The samples loaded DCP after diluting in PP powder exhibited no non-melting material up to $1000 \mathrm{ppm}$ DCP. No non-melting material indicated that DCP is homogeneously dispersed in LLDPE melt and it is more effective to the thermoinitiation process and chemical modification reaction 


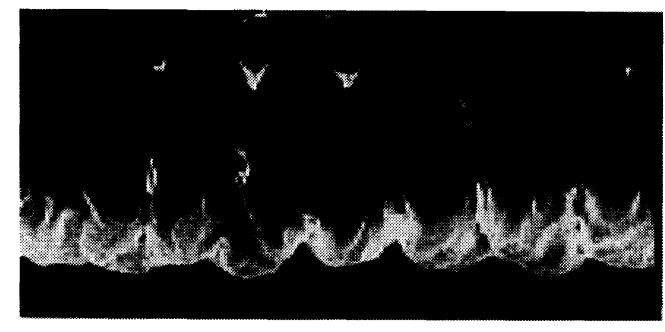

$\left(\mathrm{S}_{\mathrm{p} 650}\right)$

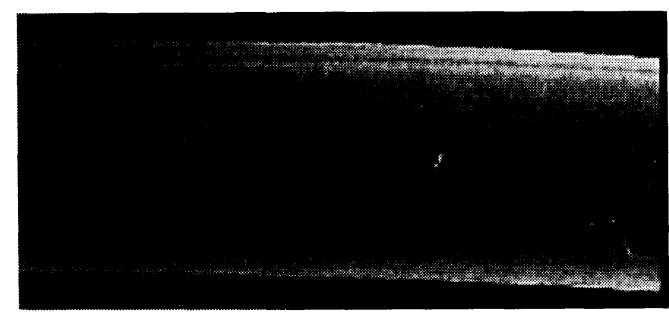

$\left(\mathrm{S}_{\mathrm{p} 850}\right)$

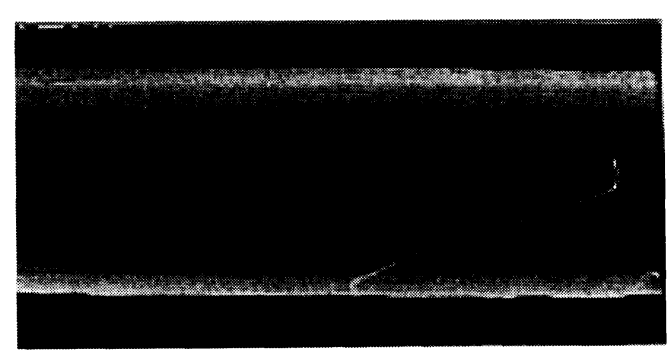

$\left(\mathrm{S}_{\mathrm{p} 1000}\right)$

Figure 2. SEM pictures of LLDPE extrudates made at $8720 \mathrm{~s}^{-1}$ in capillary rheometer as a function of DCP concentration.

when DCP is loaded in LLDPE melt after diluting in PP powder. The data including complex viscosity and melt fracture will be discussed later for both systems.

Considering the melt fracture as the second factor, there are big differences in SEM photos of extrudates at shear rate of $8720 \mathrm{~s}^{-1}$ for samples loaded DCP after diluting it in PP powder as shown in Figure 2. $\mathrm{S}_{\mathrm{p} 650}$ displayed wavy melt fracture at $8720 \mathrm{~s}^{-1}$. In contrast to the $\mathrm{S}_{\mathrm{p} 650}$, the $\mathrm{S}_{\mathrm{p} 850}$, and $\mathrm{S}_{\mathrm{p} 1000}$ displayed smooth roughness of extrudates after extrusion at $8720 \mathrm{~s}^{-1}$.

Figure 3 shows molecular weight distributions of the original LLDPE and the LLDPEs loaded DCP after diluting it in PP powder. The data show slightly increase in molecular weight distribution toward the high molecular weight portion. The presence of terminal double bonds enhanced the increase in molecular weight by participating in crosslinking and end-linking (branching) reactions. Due to a small amount of PP powder in LLDPE, the degradation reaction of PP powder caused from DCP would have little effect on crosslinking and end-linking reactions. Since the mechanism for LLDPE has been studied for several decades by many researchers and is generally accepted, ${ }^{9,12,15}$ this paper includes no further discussion for the reaction mechanism. From these results and MI (the requested MI for black jacketing material is 0.3 ) we can select the $S_{p 1000}$

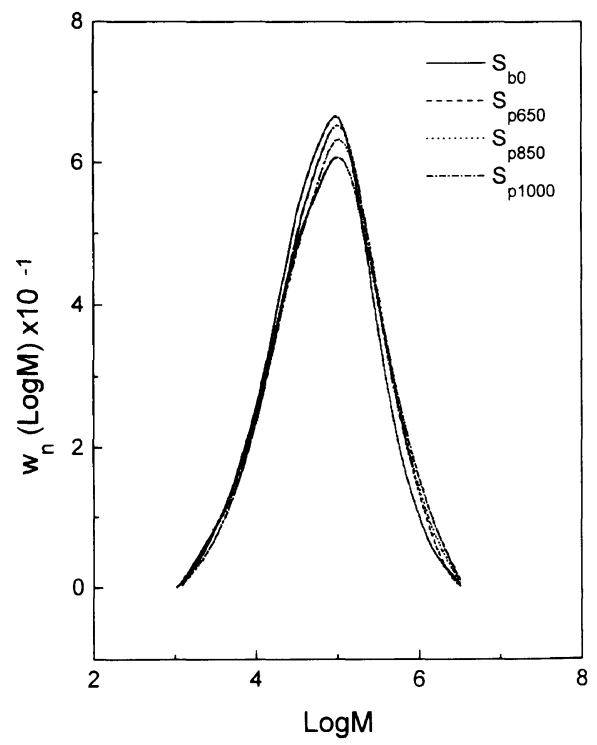

Figure 3. Gel permeation chromatographs of LLDPE resins before and after loading DCP as a function of DCP concentration.

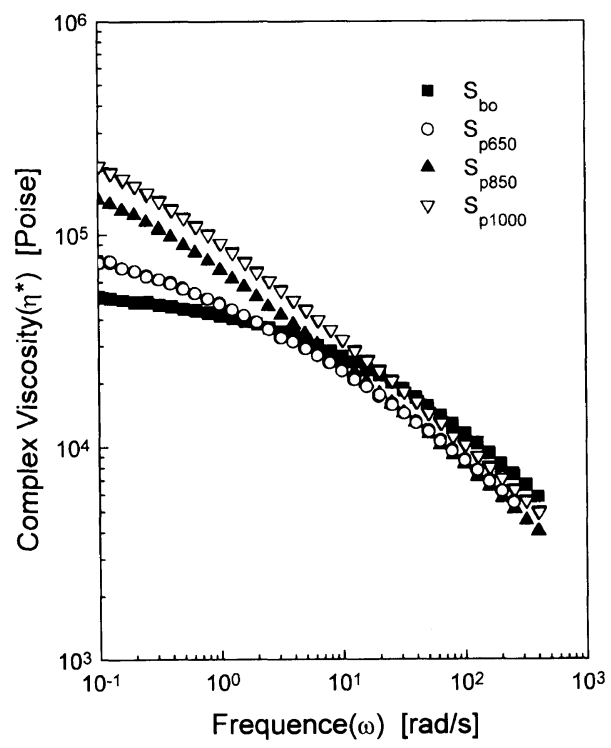

Figure 4. Complex viscosity of LLDPE resins before and after loading DCP as a function of DCP concentration.

as the best condition to improve melt fractures.

The rheological properties in molten state are very sensitive to change of molecular structure such as chain branching (or molecular weight distribution) and crosslinking. ${ }^{8,16-18}$ Oscillatory measurements were used to observe the effects of DCP modification on rheological properties of LLDPEs loaded DCP after dilution. The rheological properties obtained for LLDPE resins before and after loading DCP diluted in PP powder are shown in Figure 4 as plots of complex viscosity versus frequency. The measured temperature and strain were $200^{\circ} \mathrm{C}$ and $5 \%$, respectively. The shear sensitivity and complex viscosity at low frequency increased with DCP concentration. Bersted et al. ${ }^{17}$ reported the viscosity at low rates to increase considerably more rapidly with branching for the polyethylene samples, in which the branching was introduced by peroxide decomposition. That is, increase in high molecular portion by the formation of LCB in LLDPE resin results in increase 
in complex viscosity, shear sensitivity, and delay in the onset of melt fracture. The shear sensitivity data are summarized in Table II.

\section{Effects of DCP Loading Method on Modification} Performances

Figure 5 shows the molecular weight distributions (MWD) of the original LLDPE and LLDPEs loaded DCP for two different methods. There was no remarkable change in molecular weight distribution at high molecular weight end. GPC is not very sensitive for detecting small differences in LCB or in the high molecular weight tail whereas rheological properties have pronounced sensi-

Table II. The viscosity ratios $\left(\eta_{\omega=0.1}^{*} / \eta_{\omega=100}^{*}\right)$ of LLDPE samples

\begin{tabular}{lc}
\hline Samples & $\eta_{\omega=0.1}^{*} / \eta_{\omega=100}^{*}$ \\
\hline $\mathrm{S}_{\mathrm{b} 0}$ & 4.41 \\
$\mathrm{~S}_{\mathrm{d} 650}$ & 6.27 \\
$\mathrm{~S}_{\mathrm{d} 850}$ & 8.99 \\
$\mathrm{~S}_{\mathrm{d} 1000}$ & 13.31 \\
$\mathrm{~S}_{\mathrm{p} 650}$ & 8.58 \\
$\mathrm{~S}_{\mathrm{p} 850}$ & 17.81 \\
$\mathrm{~S}_{11000}$ & 19.87 \\
$\mathrm{~S}_{\mathrm{p} 1000}$ & 20.71 \\
\hline
\end{tabular}

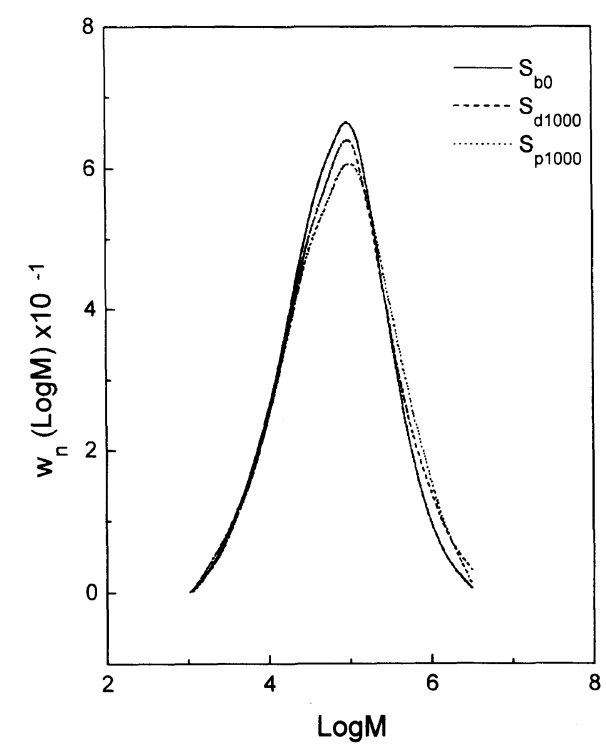

Figure 5. Gel permeation chromatographs of LLDPE resins before and after loading with two different loading methods. tivity to LCB and high molecular weight tail. Some researchers have studied rheology-to-MWD conversion using relaxation spectra. However, in the inverse rheology-to-MWD of polyolefin, the rheological data are almost never complete due to instrumental limitations. ${ }^{8}$ The limited frequency range over which storage modulus $\left(G^{\prime}\right)$ and loss modulus $\left(G^{\prime \prime}\right)$ are experimentally available (see Figure 6) makes possible the determination of a relaxation spectrum using unique discrete relaxation spectrum. ${ }^{19}$ The relaxation spectrum was minimized using by quasi-Newton algorithms having $S Q$. root $\left(\left(G_{\text {cal }}^{\prime}-G_{\text {exp }}^{\prime}\right)^{2}-\left(G_{\text {cal }}^{\prime \prime}-G_{\text {exp }}^{\prime \prime}\right)^{2}\right)$ as relative error. The results for three samples are summarized in Table III.

In Figure 6, there is a completely different pattern (shift toward left) for the DCP loaded samples. Moving toward left, of course, indicates increase in elasticity. The elastic property strongly depends on molecular structure properties such as chain branching and MWD, and increase of branching portion or high molecular weight end would explain the increase in elasticity. A simple technique has been described to quantify changes in LCB or high molecular weight end. ${ }^{7,8}$ The procedure involves extrapolating plots of $\log G^{\prime}$ against $\log G^{\prime \prime}$ to low $G^{\prime \prime}$. The following measure, called $E R$, is extracted from $G^{\prime}$ versus $G^{\prime \prime}$ data: $E R=C_{1} G^{\prime}$ at $G_{\mathrm{ref}}^{\prime \prime}$ where $G_{\mathrm{ref}}^{\prime \prime}$ is selected

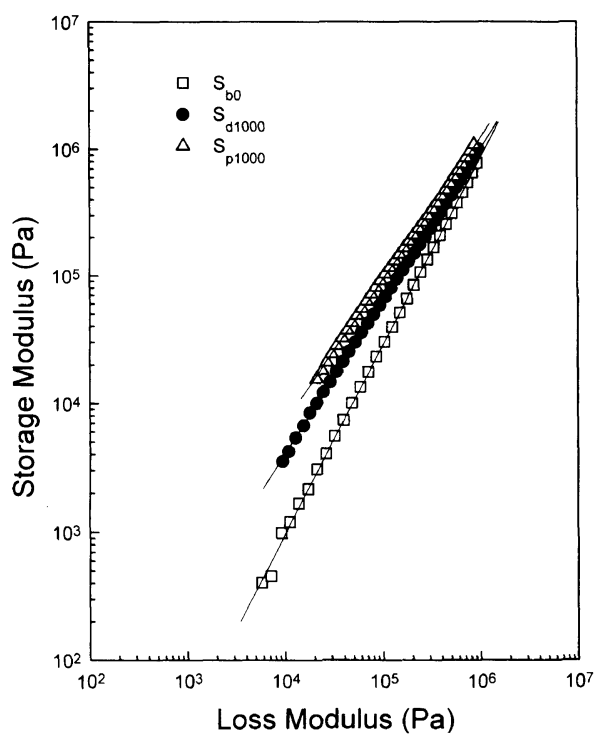

Figure 6. Plots of $\log G^{\prime}$ against $\log G^{\prime \prime}$ for three samples. Solid lines indicate linear regression.

Table III. Discrete relaxation spectra and high MW end value $(E R)$ for three samples on the $G^{\prime}$ and $G^{\prime \prime}$ at $200^{\circ} \mathrm{C}$

\begin{tabular}{|c|c|c|c|c|c|}
\hline \multicolumn{2}{|c|}{$\mathrm{S}_{\mathrm{bo}}$} & \multicolumn{2}{|c|}{$S_{d 1000}$} & \multicolumn{2}{|c|}{$S_{p 1000}$} \\
\hline$\lambda_{1}$ & $G_{\mathrm{i}}$ & $\lambda_{\mathrm{i}}$ & $G_{\mathrm{i}}$ & $\lambda_{\mathrm{i}}$ & $G_{\mathrm{i}}$ \\
\hline $3.190 \times 10^{-3}$ & 1654287 & $3.162 \times 10^{-3}$ & 1791034 & $3.162 \times 10^{-3}$ & 1551411 \\
\hline $1.468 \times 10^{-2}$ & 210483 & $2.371 \times 10^{-2}$ & 344345 & $2.371 \times 10^{-2}$ & 389471 \\
\hline $5.414 \times 10^{-2}$ & 84782 & $1.778 \times 10^{-1}$ & 91616 & $1.778 \times 10^{-1}$ & 140418 \\
\hline $1.996 \times 10^{-1}$ & 12522 & $1.333 \times 10^{-0}$ & 25097 & $1.333 \times 10^{-0}$ & 55009 \\
\hline $7.358 \times 10^{-1}$ & 4071 & $1.000 \times 10^{+1}$ & 5005 & $1.000 \times 10^{+1}$ & 24000 \\
\hline $\begin{array}{c}G^{\prime} \text { at } \\
G^{\prime \prime}=5000 \mathrm{~Pa}\end{array}$ & $E R$ & $\begin{array}{c}G^{\prime} \text { at } \\
G^{\prime \prime}=5000 \mathrm{~Pa}\end{array}$ & $E R$ & $\begin{array}{c}G^{\prime} \text { at } \\
G^{\prime \prime}=5000 \mathrm{~Pa}\end{array}$ & $E R$ \\
\hline 349 & 0.62 & 1765 & 3.14 & 3325 & 5.92 \\
\hline
\end{tabular}


to be a low modulus (corresponding to low frequencies) and $C_{1}$ is a normalization constant. $E R$ can be considered as an elasticity index normalized to remove the effects of molecular weight. For polyolefin melts, good results have been obtained with $G_{\text {ref }}^{\prime \prime}=5000 \mathrm{~Pa}$ and $C_{1}=1.781 \times$ $10^{-3}$. The basis for selecting the lowest frequencies points is that the high MW end of the MWD is reflected in the linear viscoelastic data at the lowest frequency. When available data did not extend to $G_{\mathrm{ref}}^{\prime \prime}$, (in case of $\mathrm{S}_{\mathrm{d} 1000}$ and $\left.\mathrm{S}_{\mathrm{p} 1000}\right) G^{\prime}$ at $G^{\prime \prime}=5000$ was obtained using the linear regression since a $\log -\log$ plot of $G^{\prime}$ versus $G^{\prime \prime}$ is very nearly linear in that region (see solid line of Figure 6). Sample $S_{\mathrm{p} 1000}$ shows higher $E R$ than sample $\mathrm{S}_{\mathrm{d} 1000}$ indicating increase in high $\mathrm{MW}$ portion. $E R$ for three samples are given in Table III.

The above result can be interpreted by the fact that the dilution of DCP in PP powder enhances the dispersion of DCP in LLDPE melts within limited residence time in the extruder. Examination of a blend of LLDPE with PP and no DCP was carried out to evaluate the influence of the PP carrier on melt fracture. The complex viscosity

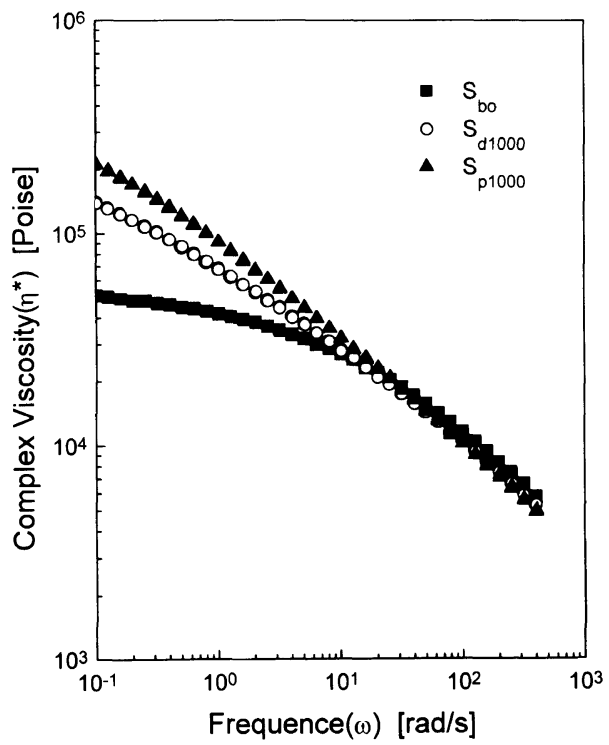

Figure 7. Complex viscosity of LLDPE resins before and after loading with two different loading methods.

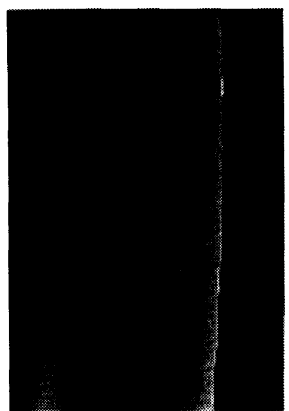

Shear Rate: $\left(\mathrm{s}^{-1}\right)$

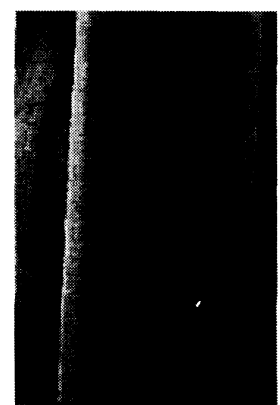

Shear Rate:

6980

$\left(\mathrm{s}^{-1}\right)$

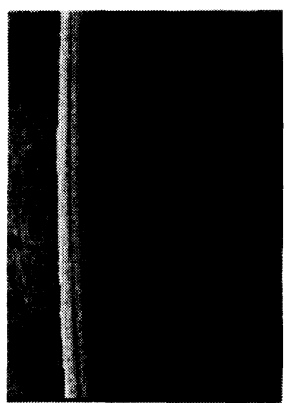

Shear Rate

$\left(\mathrm{s}^{-1}\right)$

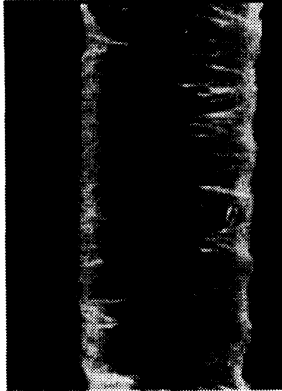

8720

$\left(\mathrm{S}_{\mathrm{b} 0}\right)$

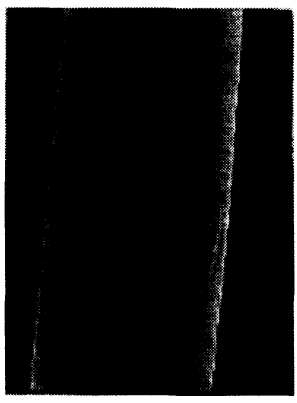

8720

$\left(\mathrm{S}_{\mathrm{d} 1000}\right)$

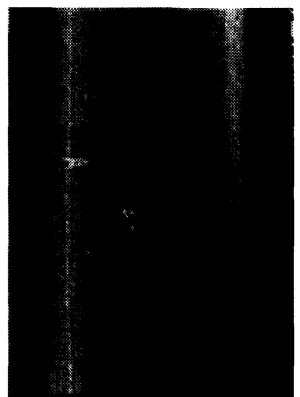

8720

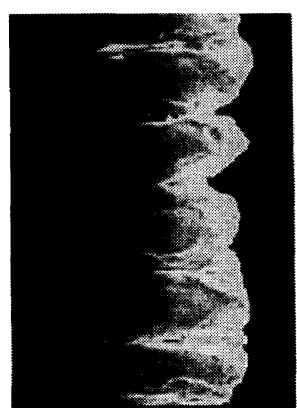

10500

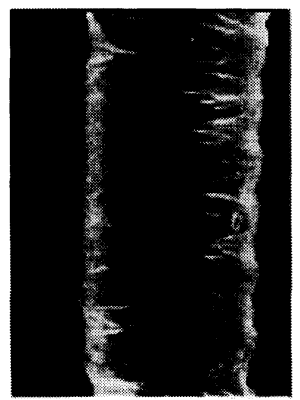

10500

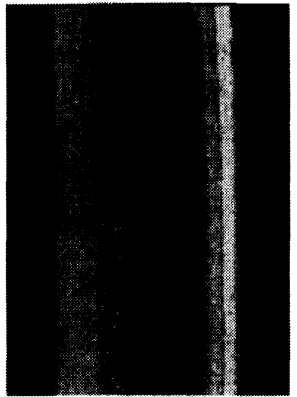

10500

$\left(\mathrm{S}_{\mathrm{p} 1000}\right)$

Figure 8. SEM pictures of LLDPE extrudates before and after loading with two different loading methods. 


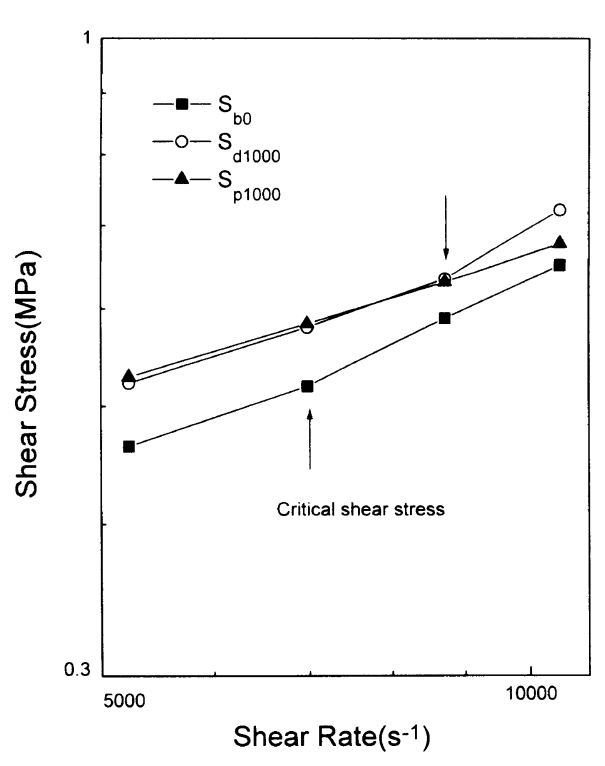

Figure 9. Apparent shear stress of the LLDPE resins before and after loading 1000 ppm DCP with two different loading methods.

and melt fracture were found to be the same. To clarify whether it is the effect of dilution of DCP or that of presence of PP powder, the same procedure was also applied to the sample with $1000 \mathrm{ppm}$ DCP after diluting in the LLDPE powder. There was no detectable change in melt fracture even if small decrease $(4 \%)$ in viscosity ratio was observed as shown in Table II.

Since long chain branching has been demonstrated to have significant effect on the complex viscosity, the complex viscosity was plotted as a function of frequency as shown in Figure $7 . \mathrm{S}_{\mathrm{p} 1000}$ displayed higher zero shear viscosity and shear sensitivity compared to the $S_{\mathrm{d} 1000}$. This indicates an additional evidence which the dilution of DCP in PP powder enhances the crosslinking and branching reaction via good dispersion of DCP in LLDPE melt.

Figure 8 shows SEM photos of extrudates as a function of shear rate. The fine scale surface distortion (sharkskin) occurs in all samples. The critical shear rate in wavy melt fractures, however, shifted toward higher value compared to original LLDPE. The wavy melt fracture occurred at $8720 \mathrm{~s}^{-1}$ for the original LLDPE and at $10500 \mathrm{~s}^{-1}$ for $\mathrm{S}_{\mathrm{d} 1000}$ but did not occurred up to $10500 \mathrm{~s}^{-1}$ for $\mathrm{S}_{\mathrm{p} 1000}$.

From several researches, ${ }^{5,20,21}$ the onset of wavy fracture was detected at critical apparent shear stress in the range $0.3-0.5 \mathrm{MPa}$ for linear polyethylene (LLDPE and HDPE). To investigate the effects of DCP treatment on the melt fracture of LLDPE resins, shear stress measurements using Hakke rheometer were performed for samples before and after DCP treatment. Figure 9 shows apparent flow curves obtained using Hakke rheometer for the $\mathrm{S}_{\mathrm{b} 0}, \mathrm{~S}_{\mathrm{d} 1000}$, and $\mathrm{S}_{\mathrm{p} 1000}$ samples. From the results of discontinuity in the apparent shear stress curves and SEM photos of extrudate, the onset of wavy melt fracture of the original LLDPE was detected at critical apparent shear stress of $0.52 \mathrm{MPa}$ as shown in Figure $9 . \mathrm{S}_{\mathrm{d} 1000}$ displayed discontinuity in the apparent shear stress curve at $8720 \mathrm{~s}^{-1}$. Discontinuity of $\mathrm{S}_{\mathrm{p} 1000}$ was not detected up to $10500 \mathrm{~s}^{-1}$ of shear rate. The critical shear stress of DCP treated samples is summarized in Table IV. Venet and Vergnes ${ }^{4}$ reported this increase
Table IV. Critical shear stresses of the LLDPEs within tested range

\begin{tabular}{lc}
\hline Samples & Shear stress/MPa \\
\hline $\mathrm{S}_{\mathrm{b} 0}$ & 0.52 \\
$\mathrm{~S}_{\mathrm{d} 650}$ & 0.54 \\
$\mathrm{~S}_{\mathrm{d} 850}$ & 0.63 \\
$\mathrm{~S}_{\mathrm{d} 1000}$ & 0.64 \\
$\mathrm{~S}_{\mathrm{p} 650}$ & 0.56 \\
$\mathrm{~S}_{\mathrm{p} 850}$ & 0.67 \\
$\mathrm{~S}_{\mathrm{p} 1000}$ & - \\
\hline
\end{tabular}

in a critical shear stress to be explained by change of molecular structure such as LCB and crosslinking. Since the LLDPE resin resulting in increase in LCB has strong strain-hardening elongational behavior able to resist high elongational stress when leaving the die, the modified LLDPE resin could be less sensitive to melt fracture.

\section{CONCLUSIONS}

The effects of DCP modification on LLDPE resin were examined by varying DCP concentration and loading method. As DCP concentration increased, the LLDPE modified by DCP had the effect of significantly increasing the high molecular portion, zero shear viscosity, and shear sensitivity in complex viscosity. The effectiveness of DCP modification increased in case of LLDPE resin loaded DCP after diluting DCP in PP powder. After modifying, the LLDPE resins exhibited a delay in the onset of melt fracture upon extrusion. The wavy melt fracture of the original LLDPE resin was detected at critical apparent shear stress in the range of $0.5-0.6$ $\mathrm{MPa}$. The wavy melt fracture of DCP treated LLDPE resin was not detected up to $0.7 \mathrm{MPa}$ of shear stress. The observed changes in high molecular portion and melt fracture can be explained by changes in LCB resulting from the chemical modification of LLDPE resin.

\section{REFERENCES}

1. B. Maxwell and A. Brockwoldt, J. Rheol., 25, 55 (1981).

2. A. Ram and L. Izrailov, J. Appl. Polym. Sci., 31, 85 (1986).

3. M.V. Prooyen, T. Bremner, and A. Rudin, Polym. Eng. Sci., 34, 570 (1994).

4. C. Venet and B. Vergnes, J. Rheol., 41, 873 (1997).

5. S. Q. Wang and P. A. Drda, Macromolecules, 29, 2627 (1996).

6. F. N. Cogswell, J. Non-Newtonian Fluid Mech., 2, 37 (1977).

7. R. Shroff, A. Prasad, and C. Lee, J. Polym. Sci., Part B, Polym. Phys., 34, 2317 (1996).

8. R. Shroff and H. Mavridis, J. Appl. Polym. Sci., 57, 1605(1995).

9. T. Bremner and A. Rudin, J. Appl. Polym. Sci., 57, 271 (1995).

10. C. Rauwendaal, "Polymer Extrusion," Hanser Publishers, Munich, 1986, p 315.

11. J. L. White, Appl. Polym. Symp., 20, 155 (1973).

12. D. Suwanda and S. T. Balke, Polym. Eng. Sci., 33, 1585 (1993).

13. D. Suwanda and S. T. Balke, Polym. Eng. Sci., 33, 1592 (1993).

14. T. Bremner and A. Rudin, J. Appl. Polym. Sci., 57, 271 (1995).

15. P. Ghosh, D. Dev, and A. Chakrabarti, Polymer, 38, 6175 (1997).

16. R. J. Koopmans, Polym. Eng. Sci., 32, 1741 (1992).

17. B. H. Bersted, J. Rheol., 30, 3751 (1985).

18. M. Baumgartel and H. H. Winter, Rheol. Acta, 28, 511 (1989).

19. S. T. Milner, J. Rheol., 40, 303 (1996).

20. I. B. Kazatchkov, S. G. Hatzikiriakos, and C. W. Stewart, Antec, 1180 (1994).

21. G. Ritzau, A. Ram, and L. Izailov, Polym. Eng. Sci., 29, 214 (1989). 